Media Farmasi p.issn 0216-2083 e.issn 2622-0962 Vol. XV No. 2, Oktober 2019,

MflMedia

Foltekkes Makassa

\title{
FORMULASI SEDIAAN MASKER GEL PEEL OFF DARI SARI BUAH DENGEN (Dillenia serrata)
}

Formulation Peel-Off Gel Mask From Dengen Fruit Extract (Dillenia Serrata)

\author{
Santi Sinala*, Amalia Afriani, Arisanty
}

Jurusan Farmasi Poltekkes Kemenkes Makassar

"Email : santisinala@poltekkes-mks.ac.id

DOI: https://doi.org/10.32382/mf.v15i2.1248

\section{ABSTRACT}

Dengen is a local fruit from North Morowali which comprises of various compounds such as tannins, saponins, and flavonoids. However, it possesses antioxidant activity that needs to be developed into a peel-off gel mask for maximum utility. This study, therefore, aims to make a peel-off gel mask formula from Dengen fruit extracts to determine its physical quality stability. The formulations were prepared with various concentrations of polyvinyl alcohol (PVA) in 10\%, 12.5\%, 15\%. Physical quality testing was carried out before and after accelerating the storage conditions (freeze thaws), which includes the tests of organoleptic, homogeneity, $\mathrm{pH}$, dispersal power, viscosity, and dry time. The research showed that Dengen fruit has the ability to be formulated into a peel-off gel mask with polyvinyl alcohol (PVA) base 10\%, 12.5\%, $15 \%$. Furthermore, the physical quality results show that all formulas fulfill the requirements, and $15 \%$ polyvinyl alcohol (PVA) has the best dry time.

Keywords: Peel off gel mask, Physical quality, Dengen Fruit and PVA.

\begin{abstract}
ABSTRAK
Buah dengen adalah buah lokal yang berasal dari Morowali Utara dengan berbagai kandungan senyawa di dalamnya seperti tanin, saponin dan flavonoid serta memiliki aktivitas antioksidan yang pengunaannya belum dimanfaatkan secara maksimal, sehingga perlu dikembangkan dalam suatu formula yang praktis seperti masker gel peel off. Penelitian ini bertujuan untuk membuat formula sediaan masker gel peel off dari sari buah Dengen serta untuk mengetahui stabilitas mutu fisik dari sediaan masker gel peel off. Formulasi sediaan masker gel peel off dibuat dengan variasi konsentrasi polivinil alcohol (PVA) 10\%, 12,5\%, $15 \%$. Pengujian mutu fisik dilakukan sebelum dan sesudah kondisi penyimpanan dipercepat (frezze thaw) meliputi uji organoleptis, uji homogenitas, uji $\mathrm{pH}$, uji daya sebar, uji viskositas dan uji waktu kering. Berdasarkan penelitian buah Dengen dapat diformulasikan menjadi sediaan masker gel peel off dengan basis polivinil alcohol (PVA) 10\%, 12,5\%, 15\%. Hasil mutu fisik sediaan menunjukan bahwa semua formula memiliki mutu fisik yang memenuhi syarat dan polivinil alcohol (PVA) $15 \%$ memiliki waktu kering paling baik.
\end{abstract}

Kata kunci: Masker gel peel off, Mutu fisik, Buah Dengen dan PVA.

\section{PENDAHULUAN}

Lapisan terluar dari tubuh manusia adalah kulit yang juga berfungsi menjadi pelindung pertama tubuh kita dari paparan sinar matahari. Terutama kulit pada bagian wajah yang cenderung selalu terpapar sinar ultraviolet (UV) dan dapat menimbulkan banyak masalah pada kulit seperti penuaan dini, keriput, jerawat juga masalah kulit yang lainnya, maka dari itu kita harus selalu mejaga dan memelihara kesehatan kulit kita (Grace et al., 2015). Untuk mencegah masalah masalah pada kulit wajah dibutuhkan perawatan kecantikan, salah satu produk yang sangat popular dan dapat meningkatkan kualitas kulit kita adalah masker pada wajah (Yeom et al., 2011). Salah satu dari banyaknya masker yang ada di pasaran adalah yang disebut Masker wajah peel off. Masker ini banyak disukai oleh orang orang karena penggunaaanya yang praktis yaitu setelah kering dapat diangkat atau dikelupas seperti membrane elastis (Rahmawanty dkk., 2015). Kegunaan lain dari masker wajah peel off ini adalah menghindarkan kulit wajah dari kusam dan kering yang disebakan oleh paparan sinar UV (Velasco et al ., 2014). 
Dalam pembuatan kosmetik menggunakan bahan alami lebih baik dari pada bahan sintesis yang dapat menimbulkan efek samping dan merusak bentuk alami dari kulit (Grace et al., 2015). Dalam pembuatan masker wajah pell off maka diformulasikan dengan basis polivinil alkohol (PVA), maka setelah pengolesan dan pengeringan akan terbentuk lapisan oklusif pada wajah (Farmaka Volume 14 Nomor 319) (Vieira et al., 2009). Bahan bahan tambahan seperti bahan pelunak, pengawet, pelembab, pewangi, surfaktan dan zat aktif sangat dibutuhkan dalam membantu efek kolusi dan tensor meningkat (Zague et al., 2008).

Sifat adhesive yang dimiiki oleh polivinil alkohol (PVA) akan membantu memberikan efek lapisan film yang disebut efek peel off yang nantinya setelah kering akan mudah mengelupas (Brick et al., 2014). Yang menjadi hal penting dalam proses pembentukan film masker wajah peel off ini adalah konsentrasi dari polivinil alkohol (PVA) itu sendiri (Beringhs et al., 2013). Hal lainnya yang sangat berpengaruh dalam formulasi masker wajah gel peel off adalah Konsentrasi humektan karena sangat mempengaruhi viskositas dan waktu pengeringan sediaan (Rahmawanty dkk., 2015; Barel et al., 2009).

Salah satu buah lokal dari Sulawesi Tengah adalah buah Dengen yang tersebar luas kabupaten Morowali utara. Tanaman ini sangat mudah kita jumpai karena banyak terdapat pada halaman warga setempat dan juga tumbuh liat dibeberapa tempat seperti hutan. Yang menjadi ciri khas dari buah ini adalah rasa asam yang menyegarkan dan juga warnanya yang menarik, dan tak lupa pula buah dengen ini kaya akan vitamin C dengan presentase 84\% (Crashed, 2009).

Menurut hasil penelitian yang dilakukan oleh Reny syahruni, Syamsu Nur (2015) skrining komponen kimia ekstrak etanol buah dengen mengandung tanin, saponin dan flavonoid. Kadar flavonoid total berdasarkan nilai kesetaraan rutin $15,25 \mu \mathrm{g} / \mathrm{ml}$ diperoleh sebesar 3,05 \%. Aktivitas antioksidan ditunjukkan oleh ekstrak etanol buah dengen, yaitu dengan menggunakan fraksi etil asetat, fraksi air asetat dan fraksi heksan. Aktivitas antioksidan yang ditentukan berdasarkan metode DPPH menunjukkan bahwa ekstrak etanol buah dengen, fraksi air, fraksi etil asetat dan fraksi heksan memiliki aktivitas sebagai antioksidan dengan nilai 103 ppm. Aktivitas antioksidan fraksi air lebih kuat dibandingkan fraksi etil asetat, fraksi heksan dan ekstrak etanol buah dengen.
Berdasarkan uraian di atas maka dilakukan penelitian formulasi dan uji stabilitas Sediaan masker gel peel off dari Sari buah dengen (Dillenia serrata Linn.).

Rumusan masalah dari penelitian ini adalah apakah sari dari Buah Dengen (Dillenia serrata Linn.) dapat diformulasi menjadi sediaan masker Gel Peel Off dan bagaimana stabilitas dan mutu fisik dari sediaan masker Gel peel-off yang dibuat dari sari buah Dengen (Dillenia serrata Linn.). Tujuan Penelitian dari penelitian ini adalah untuk membuat formula sediaan masker Gel peel-off yang dibuat dari sari dari buah Dengen (Dillenia serrata Linn.) dan Untuk mengetahui stabilitas mutu fisik dari sediaan masker Gel peel-off yang dibuat dari sari buah Dengen (Dillenia serrata Linn.)

\section{METODE \\ Jenis Penelitian}

Jenis penelitian ini adalah eksperimen laboratorium, desain penelitian pretest posstest design, untuk menformulasi sediaan masker wajah bentuk gel peel off dari sari buah Dengen dan meguji mutu fisiknya yang meliputi organoleptik, uji homogenitas, pengukuran $\mathrm{pH}$, pengukuran daya sebar dan waktu kering sediaan sebelum dan sesudah pengujian stabilitas dipercepat.

\section{Tempat dan Waktu Penelitian}

Penelitian ini telah dilaksanakan pada bulan Februari - Mei 2019 di Laboratorium Teknologi Sediaan Farmasi Jurusan Farmasi Politeknik Kesehatan Kementrian Kesehatan Makassar.

\section{Teknik Pengumpulan}

Sampel buah Dengen (Dillenia serrata Linn.) diperoleh dari Kabupaten Morowali Utara, Sulawesi Tengah

\section{Pengolahan Sampel}

Sampel yang telah diperoleh dicuci bersih lalu dipisahkan dari kulitnya. Kemudian di juicer dan saring ke dalam wadah, setelah itu sampel akan dikeringkan di freeze dryer.

\section{Alat dan Bahan}

Adapun alat yang digunakan dalam penelitian ini adalah, batang pengaduk, cawan porselin, climetic chamber, corong, freeze dryer, gelas kimia, gelas ukur, hot plate, juicer, kaca gelas arloji, lumpang, pipet tetes, $\mathrm{pH}$ universal, sudip, sendok tanduk, timbangan analitik. Sedangkan bahan yang digunakan dalam penelitian ini antara lain, aqua destillata, sari buah Dengen (Dillenia serrata Linn.), Hydroxy propyl methyl cellulose (HPMC), Nipagin, propilenglikol dan polivinil Alkohol (PVA). 


\section{Prosedur Penelitian}

Masker peel-off dibuatkan berdasarkan formula pada tabel 1 .

Tabel 1. Formula masker gel peel-off

\begin{tabular}{lcccc} 
& \multicolumn{3}{c}{ Konsentrasi (\%) } & $\begin{array}{c}\text { Konsentrasi (\%) } \\
\text { Bahan }\end{array}$ \\
\cline { 2 - 4 } Sari Buah & F1 & F2 & F3 & 10 \\
PVA & 10 & 10 & 15 & $10-16$ \\
HPMC & 10 & 12,5 & 2 & $1-4$ \\
Prophilenglikol & 2 & 2 & 10 & $10-25$ \\
Nipagin & 10 & 10 & 0,2 & $0,02-0,3$ \\
Aqua Destillata & Ad 100 & Ad 100 & Ad 100 & \\
\hline
\end{tabular}

Polivinil alcohol (PVA) dan Hydroxy propyl methyl cellulose (HPMC), dikembangkan dengan aquadest suhu $90^{\circ} \mathrm{C}$ secara terpisah. Setelah polivinil alcohol (PVA) dan Hydroxy propyl methyl cellulose (HPMC) mengembang dan homogen, maka keduanya dicampurkan dan diaduk dengan pengadukan yang konstan hingga homogen. Lalu dituangkan nipagin yang telah dipanaskan dengan aquadest ke dalam lumpang yang berisi polivinil alcohol (PVA) dan Hydroxy propyl methyl cellulose (HPMC), diaduk hingga homogen. Kemudian sari buah Dengen yang telah dilarutkan dengan propilenglikol dimasukkan kedalam lumpang sedikit demi sedikit sambil terus dilakukan pengadukan agar tercipta gel yang homogen.

\section{Evaluasi Sediaan Masker Gel peel-off (Dillenia serrata Linn.).}

Evaluasi stabilitas sediaan Masker Gel peel-off (Dillenia serrata Linn.) dilakukan untuk mengetahui stabilitas sediaan sebelum dan sesudah diberi perlakuan penyimpanan dipercepat menggunakan climatic chamber. Uji ini akan dilakukan berdasarkan pengaruh suhu (freeze thaw). Kontrol sediaan disimpan pada suhu $25^{\circ} \mathrm{C}$ dan siklus freeze thaw sediaan disimpan pada suhu $5^{\circ} \mathrm{C}$ dan $35^{\circ} \mathrm{C}$ masingmasing selama 12 jam sebanyak 6 siklus. Dan sediaan yang diperlakukan freeze thaw sebanyak 6 siklus. Evaluasi kestabilitas mutu fisik meliputi

a. Pengamatan Organoleptik

Pengujian pertama yang dilakukan adalah pengujian organoleptic. Hal-hal yang akan diamati adalah ada atau tidaknya perubahan seperti bau, bentuk, ataupun warna sediaan yang dilakukan setelah pembuatan basis. Biasanya sediaan dengan konsentrasi setengah padat akan jernih (Septiani, 2011). b. Pengujian Homogenitas.

Uji homogenitas dilakukan dengan cara sampel diletakkan di antara dua kaca objek lalu amati ada tidaknya partikel kasar yang berada dalam sediaan. Sediaan dinyatakan homogen apabila warnanya telah sama, tidak terdapat partikel atau bahan bahan yang kasar (Syamsuni, 2005).

c. Pengujian Viskositas

Sediaan masker gel peel off dengan jumlah $100 \mathrm{ml}$ akan ditempatkan pada Viskometer stormer, lalu atur spindle serta kecepatan yang diinginkan lalu dijalankan, tunggu dan beberapa saat kemudian hasil viskositas akan terbaca dengan sendirinya (Septiani, 2011). Dalam sediaan gel peel-off yang baik nilai viskositas baik yaitu 20004000 cps (Garg et al., 2002).

d. Pengujian $\mathrm{pH}$

Pengujian $\mathrm{pH}$ dengan menggunakan stik pH universal yang akan dimasukkan pada sampel yang telah dilarutkan dengan aquadest lalu liat perubahan warna pada stik dan cari warna yang sama pada indikator $\mathrm{pH}$ universal, syarat $\mathrm{pH}$ untuk kulit yaitu 4,5 6,5 (Tranggono, 2007).

e. Pengujian Daya Sebar.

Diletakkan sediaan gel peel off diatas kaca A yang berukuran 20 × $20 \mathrm{~cm}$ sebanyak 1 gram. Lalu tutup kaca A dengan kaca yang lainnya dengan kode B dan berikan diatasnya pemberat hingga bobot yang dicapai 100 gram. Setelah 1 menit akan diukur diameternya, syarat daya sebar yang baik yaitu 5-7 cm (Garg et al., 2002).

f. Pengujian Waktu Sediaan Mengering

Dioleskan masker gel peel-off ekstrak etanol buah dengen pada bagian punggung tangan lalu kita amati dengan seksama waktu yang digunakan hingga sediaan mongering, terhitung saat dioleskan hingga membentuk lapisan yang telah mengering. 
15 - 30 adalah menit syarat waktu lama sediaan tersebut mengering (Slavtcheff, 2000), setelah itu dilakukan perbandingan waktu kering masket tersebut dengan produk yang ada dipasaran (Vieira, et al,. 2009).

\section{Pengolahan data}

Data yang diperoleh kemudian dianalisa pendekatan teoritis dengan membandingkan antara hasil uji mutu fisik sediaan masker gel

wajah Sari buah Dengen meliputi pengamatan organoleptic, homogenitas, $\mathrm{pH}$, viskositas, daya sebar dan waktu kering. Selanjutnya ditarik suatu kesimpulan.

\section{HASIL} di bawah ini

Hasil penelitian digambarkan pada table

Tabel 2. Hasil pengamatan organoleptis sediaan masker gel peel-off sari buah Dengen sebelum dan sesudah uji penyimpanan dipercepat selama 6 siklus menggunakan climatic chamber.

\begin{tabular}{cccccccc}
\hline \multirow{2}{*}{ No } & \multirow{2}{*}{ Formula } & \multicolumn{6}{c}{ Organoleptis } \\
\cline { 3 - 7 } & & \multicolumn{2}{c}{ Sebelum Penyimpanan dipercepat } & \multicolumn{2}{c}{ Sesudah Penyimpanan dipercepat } \\
\cline { 3 - 7 } & Konsistensi & Warna & Bau & Konsistensi & Warna & Bau \\
\hline 1. & F1 & Agak Kental & Kuning gelap & Khas & Agak kental & Kuning gelap & Khas \\
2. & F2 & Kental & Kuning gelap & Khas & kental & Kuning gelap & Khas \\
3. & F3 & Sangat kental & Kuning gelap & Khas & Sangat kental & Kuning gelap & Khas \\
\hline
\end{tabular}

Data primer 2019

Tabel 3. Hasil pengamatan homogenitas sediaan masker gel peel-off sari buah Dengen sebelum dan sesudah uji penyimpanan dipercepat selama 6 siklus menggunakan climatic chamber.

\begin{tabular}{cccccc}
\hline No & Formula & $\begin{array}{c}\text { Sebelum Penyimpanan } \\
\text { dipercepat }\end{array}$ & $\begin{array}{c}\text { Sesudah Penyimpanan } \\
\text { dipercepat }\end{array}$ & Persyaratan & Hasil \\
\hline 1. & F1 & Homogen & Tidak ada perubahan & $\begin{array}{l}\text { Pada sediaan } \\
\text { tidak terlihat } \\
\text { adanya } \\
\text { butiran kasar }\end{array}$ & Memenuhi syarat \\
2. & F2 & Homogen & Tidak ada perubahan & Memuhi syarat \\
3. & F3 & Homogen & Tidak ada perubahan & Memenuhi syarat
\end{tabular}

Data primer 2019

Tabel 4. Hasil pengamatan pH sediaan masker gel peel-off sari buah Dengen sebelum dan sesudah uji penyimpanan dipercepat selama 6 siklus menggunakan climatic chamber.

\begin{tabular}{cccccc}
\hline No & Formula & $\begin{array}{c}\text { Sebelum } \\
\text { Penyimpanan }\end{array}$ & $\begin{array}{c}\text { Sesudah } \\
\text { Peyimpanan }\end{array}$ & Persyaratan & Hasil \\
\hline 1 & F1 & 5 & 5 & & Memenuhi syarat \\
2 & F2 & 5 & 5 & $4,5-6,5$ & Memenuhi syarat \\
3 & F3 & 5 & 5 & & Memenuhi syarat
\end{tabular}

Data primer 2019

Tabel 5. Hasil pengamatan Daya sebar sediaan masker gel peel-off sari buah Dengen sebelum dan sesudah uji penyimpanan dipercepat selama 6 siklus menggunakan climatic chamber.

\begin{tabular}{cccccc}
\hline No & Formula & $\begin{array}{c}\text { Sebelum penyimpanan } \\
\text { dipercepat }\end{array}$ & $\begin{array}{c}\text { Sesudah penyimpanan } \\
\text { dipercepat }\end{array}$ & Persyaratan & Hasil \\
\hline 1. & F1 & $6,5 \mathrm{~cm}$ & $5,5 \mathrm{~cm}$ & Memenuhi syarat \\
2. & F2 & $6 \mathrm{~cm}$ & $5 \mathrm{~cm}$ & $5-7 \mathrm{~cm}$ & Memenuhi syarat \\
3. & F3 & $5,5 \mathrm{~cm}$ & $5,3 \mathrm{~cm}$ & & Memenuhi syarat \\
\hline
\end{tabular}

Data primer 2019 
Tabel 6. Hasil pengamatan Daya sebar sediaan gel peel-off sari buah Dengen sebelum dan sesudah uji penyimpanan dipercepat selama 6 siklus menggunakan climatic chamber.

\begin{tabular}{cccccc}
\hline No & Formula & $\begin{array}{c}\text { Sebelum penyimpanan } \\
\text { dipercepat }\end{array}$ & $\begin{array}{c}\text { Sesudah penyimpanan } \\
\text { dipercepat }\end{array}$ & Persyaratan & Hasil \\
\hline 1. & F1 & 2118 & 2202 & Memenuhi syarat \\
2. & F2 & 2687 & 3137 & $2.000-4.000$ & Memenuhi syarat \\
3. & F3 & 2693 & 3377 & & Memenuhi syarat \\
\hline
\end{tabular}

Data primer 2019

Tabel 7. Hasil pengamatan waktu kering sediaan gel peel-off sari buah Dengen sebelum dan sesudah uji penyimpanan dipercepat selama 6 siklus menggunakan climatic chamber.

\begin{tabular}{ccccc} 
No. & Formula & $\begin{array}{c}\text { Sebelum penyimpanan } \\
\text { dipercepat }\end{array}$ & $\begin{array}{c}\text { Setelah penyimpanan } \\
\text { dipercepat }\end{array}$ & Persyaratan \\
\hline 1 & F1 & 26 & 24 & $<30$ menit \\
2 & F2 & 22 & 20 & \\
3 & F3 & 19 & 16 & \\
\hline
\end{tabular}

Data primer 2019

Keterangan : $\quad$ F1 : PVA $10 \%$

F2 : PVA $12,5 \%$

F3 : PVA $15 \%$

\section{PEMBAHASAN}

Pada penelitian ini telah dibuat sediaan masker gel peel-off dengan menggunakan bahan aktif Buah Dengen (Dillenia serrata L), berdasarkan penelitian sebelumnya yang dilakukan oleh Reny syahruni, Syamsu Nur (2015) skrining komponen kimia ekstrak etanol buah dengen mengandung tanin, saponin dan flavonoid. Kadar flavonoid total berdasarkan nilai kesetaraan rutin $15,25 \mu \mathrm{g} / \mathrm{ml}$. diperoleh sebesar 3,05 \%. Aktivitas antioksidan ditunjukkan oleh ekstrak etanol buah dengen, yaitu dengan menggunakan fraksi etil asetat, fraksi air asetat dan fraksi heksan. Aktivitas antioksidan fraksi air lebih kuat dibandingkan fraksi etil asetat, fraksi heksan dan ekstrak etanol buah dengen.

Penelitian ini dibuat masker gel peel-off buah Dengen (Dillenia serrata L), dengan menvariasikan konsentrasi polivinil alcohol (PVA) $10 \%$, 12,5\%, dan 15\% dalam formula berperan sebagai pembentuk lapisan film, lapisan film yang terbentuk dapat diangkat dengan mudah tanpa retak atau robek.

Pada formula masker gel peel-off ini juga mengguakan bahan tambahan lain seperti Hydro Propyl Metyl Celullose (HPMC) sebagai gelling agent (bahan tambahan yang digunakan untuk mengentalkan dan memberikan tekstur melalui pembentukan gel), propilenglikol sebagai humektan yang menjaga kestabilan sediaan gel dengan cara mengurangi penguapan air dari sediaan, metyl paraben sebagai pengawet mikroba dalam formula serta aquadest untuk melarutkan dan mencukupan volume sediaan.

Sediaan masker gel peel-of dari buah dengen dilakukan pengujian mutu fisik yaitu penyimpanan dipercepat dengan metode freeze thaw sebanyak 6 siklus menggunakan climatic chamber dengan parameter-parameter yang diukur yaitu pengamatan organoleptis, uji $\mathrm{pH}$ sediaan, uji homogenitas, uji daya sebar, uji viskositas dan uji waktu kering.

Pengamatan organoleptis sediaan masker gel peel-off Buah Dengen (Dillenia Serrata L) yang meliputi warna, bau dan bentuk sediaan. Hasil data dari pengamatan organoleptis pada ketiga formula yaitu dengan kosentrasi polivinil alcohol 10\%, 12,5\% dan 15\% sebelum penyimpanan diperoleh hasil warna kuning gelap berbau khas dengan konsistensi yang berbeda. Adapun hasil yang diperoleh setelah penyimpanan yaitu warna, bau tetap khas dan konsisten sediaan tetap seperti sebelum penyimpanan, sehingga tidak ada perubahan dalam sediaan.

Uji homogenitas adalah salah pengujian yang penting dalam pembuatan sediaan farmasetik karena bertujuan untuk mengetahui apakah bahan-bahan dalam formulasi tersebut telah tercampur homogen atau tidak. Pengujian ini penting untuk dilakukan untuk mengetahui 
apakah bahan - bahan yang telah dicampurkan telah terdistribusi merata dan tidak ada partikelpartikel yang menggumpal sehingga hasil yang diperoleh maksimal. Pengamatan homogenitas ini dilakukan saat sediaan dioleskan pada kaca transparan dibawah cahaya. Seperti pada tabel 3 ditunjukkan bahwa sediaan masker gel peel-off buah Dengen (Dillenia serrata L) dari ketiga formula sebelum dan setelah penyimpanan dipercepat menunjukkan homogenitas yang baik dan memenuhi syarat.

Uji pH yang dilakukan untuk mengetahui keamanan suatu dari sediaan terutama sediaan topikal. Syarat sediaan topikal mempunyai nilai $\mathrm{pH}$ yang sama dengan $\mathrm{pH}$ kulit, hal ini untuk menghindari iritasi yang dapat timbul pada permukaan kulit. Hasil yang diperoleh dari pengujian $\mathrm{pH}$ sediaan masker peel-off dari ketika formula sebelum dan setelah penyimpanan diperoleh $\mathrm{pH}$ yang sama dan memenuhi kriteria $\mathrm{pH}$ kulit, jadi dapat disimpulkan bahwa nilai $\mathrm{pH}$ ketiga formula sesuai dengan persyaratan (tabel 4).

Pengujian daya sebar pada setiap sediaan masker gel peel-off Buah Dengen (Dillenia serrata L) menunjukkan adaya perubahan sebelum dan sesudah penyimpanan. Uji daya sebar pada table 5 menunjukkan bahwa semakin tinggi konsentrasi PVA maka semakin rendah daya sebarnya.penurunan daya sebar ini sejalan dengan peningkatan viskositas. Dari hasil uji daya sebar menunjukkan bahwa semakin tinggi konsentrasi PVA maka daya sebar akan semakin menurun. Apabila tekanan yang diberikan sama pada setiap formula masker, maka semakin kental sediaan tersebut kemampuan sebar yang dihasilkan akan semakin kecil. Pada ketiga formula yang telah diujikan sebelum dan sesudah penyimpanan telah memenuhi syarat daya sebar yang baik.

Uji viskositas atau kekentalan gel dilakukan menggunakan alat viskometer dengan pembacaan dibaca pada $100 \mathrm{rpm}$ menggunakan spindle nomor 3. Semakin tinggi nilai viskositas sediaan gel maka kemampuan tahanannya akan semakin tinggi pula (Puspitasari, 2018). Hasil pengujian pada tabel 6 menunjukkan bahwa viskositas tertinggi terdapat pada formula tiga dan viskositas terendah terdapat pada formula satu baik sebelum maupun setelah penyimpanan pada climatic chamber

Uji waktu kering sediaan dimonitor hingga sediaan mengering dan sediaan yang dioleskan dapat dikuliti atau peel-off dari tabel 7 dapat diketahui bahwa F1, F2 dan F3 memenuhi syarat waktu kering $<30$ menit. Waktu mengering dipengaruhi oleh kadar air yang terdapat dalam sediaan, semakin banyak kadar air yang terdapat maka waktu mongering semakin meningkat serta adanya pengaruh dari ketebalan yang dioleskan. Parameter uji waktu mengering kurang dari 30 menit (Vierra dkk, 2009).

\section{KESIMPULAN}

Berdasarkan hasil penelitian yang telah dilakukan, diperoleh kessimpulan bahwa sari buah dengen (Dillenia serrata L) dapat diformulasikan ke dalam bentuk sediaan masker gel peel-off dengan variasi konsentrasi Polivenil Alkohol dimana pada konsentrasi PVA sebesar $15 \%$ menunjukkan waktu kering yang paling baik.

\section{SARAN}

Dari hasil penelitian yang diperoleh maka disarankan untuk penelitian selanjutnya melakukan pengujian iritasi dan pengujian cemaran pada sediaan.

\section{DAFTAR PUSTAKA}

Barel, A. O., M. Paye, and H.I Maibach. 2009. Handbook of Cosmetic Science and Technology. New York: Informa Healthcare USA, Inc.

Beringhs, A.O., M.R. Julia, K.S. Hellen, M.B. Rosane, and S. Diva. 2013. Green clay and aloe vera peel-off facial masks: response surface methodology applied to the formulation design. AAPS Pharm Sci Tech. 14 (1): 445-455.

Garg, A., A. Deepika, S. Garg, and A. K. Sigla. (2002). Spreading of semisolid formulation. USA : Pharmaceutical Tecnology. Pp. 84-104.

Grace, F.X., C. Darsika, K.V. Sowmya, K. Suganya, and S. Shanmuganathan. 2015. Preparation and Evaluation of Herbal Peel Off Face Mask. American Journal of PharmTech Research. (5): 33-336

Rahmawanty, Dina., Nita. Yulianti, dan Mia.Fitriana.2015. Formulasi dan Evaluasi Masker Wajah Peel-Off Mengandung Kuersetin Dengan Variasi Konsentrasi Gelatin dan Gliserin."Media Farmasi. 12 (1): 17-32.

Syahrun Reny, 2017, Identifikasi Komponen Kimia Dan Uji Daya Antioksidan Ekstrak Buah Dengen (Dillenia serrate thunbr.), Akademi Farmasi Kebangsaan Makassar,: Makassar. 
Septiani, S., Wathoni, N., Mita, S.R., 2011. Formulasi Sediaan Masker Gel Antioksidan Dari Ekstrak Etanol Biji

Tranggono, R.I., dan F. Latifah. (2007). Buku Pegangan Ilmu Pengetahuan Kosmetik. PT. Gramedia, Jakarta.

Vieira, R.P., A.R. Fernandes, T.M. Kaneko, V.O. Consiglieri, C.A.S.O. Pinto, et al. 2009.Physical and Physicochemical Stability Evaluation of Cosmetic Formulations Containing Soybean Extract
Fermented by Bifidobacterium animalis.Brazilian Journal of Pharmaceutical Sciences. 45 (3): 515-525.

Velasco, M.V.R., et al. 2014. Short-term clinical of peel-off facial mask moisturizers.International Journal of Cosmetic Science. 36: 355-360.

Wulan Safitri, 2017, Uji Fitokimia Ekstrak Buah Dengen, Fakultas Sains Universitas Cokroaminoto,: Palopo. 